\section{Comércio Eletrônico em Agências de Viagens - Estratégias Competitivas e de Marketing}

\section{Geraldo Luciano Toledo ${ }^{1}$ Léo Sztutman Jacques Melul Rubal}

RESUMO: Discute o comércio eletrônico na estratégia competitiva de empresas de serviços, analisando os conceitos que lhe são pertinentes, o ambiente de marketing na indústria turística e aspectos do comércio eletrônico. São apresentados resultados de estudo de caso em duas agências de viagem.

PALAVRAS-CHAVE: comércio eletrônico, estratégica competitiva, indústria turística, internet, agência de viagem.

ABSTRACT: This paper discuss some significant issues of the electronic commerce and its implication on the competitive strategy of a service company. Afteranalyzing some concepts of competitive strategy, it is presents a overview of the marketenvironment in the tourism industry and describes some relevant aspects of electronic commerce through internet. Finally, the results of a case study concerning two travel agencies are commented.

KEYWORDS: electronic commerce, competitive strategy, tourism industry, internet, travel agencie.

\footnotetext{
1. Professor Titular do Departamento de Administraçāo da Faculdade de Economia e Administraçāo da Universidade de São Paulo.

E-mail: gltoledo@usp.br

2. Mestrando em Turismo pela Escola de Comunicaçōes e Artes da Universidade de São Paulo.

E-mail: leosztutman@yahoo.com.b

3. Mestrando em Administração pela Faculdade de Economia e Administração da Universidade de São Paulo. E-mail: jmrubal@usp.br
}

Introduçāo

O comércio eletrônico tem se revelado uma forma eficiente e promissora de intermediário de troca da qual podem servir-se muitas empresas fornecedoras de determinados tipos de produtos e de serviços. Para alcançarem seus objetivos, as empresas, que ingressaram na era do comércio eletrônico, têm procurado desenvolver um trabalho de marketing diferenciado daquele utilizado tradicionalmente pelo varejo e por outras organizações de serviços. Neste contexto, as agências de turismo figuram como um ilustrativo exemplo para analisar as possibilidades de diferenciação na prestação de serviços, bem como a mudança de comportamento dos consumidores dessa modalidade de canal e a forma como percebem os atributos dos serviços oferecidos.

O objetivo deste artigo é analisar, por meio de um estudo exploratório, o emprego de novas tecnologias, em particular do comércio eletrônico via internet, como instrumento que possibilita agregar valor ao cliente de empresas de serviços. Especificamente, pretende-se discutir o uso do comércio eletrônico por agências de turismo, com o recurso da internet, e avaliar como isso pode proporcionar a agências um diferencial no âmbito da indústria do turismo, tendo por base o conceito de vantagem competitiva, a presença das forças componentes do ambiente em que atuam e a formulação de estratégias competitivas. Procurou-se, ainda, descrever o ambiente de marketing na indústria do turismo, de modo a identificar os partners, as interações com as forças e entidades externas e as tendências das empresas no Brasil. Incluíram-se, por último, os resultados de estudo de caso referentes a duas agências de viagens com sites na internet; uma delas especializada no atendimento a pessoas jurídicas, e outra direcionada para o público em geral. Foram verificados ainda aspectos relativos às expectativas futuras quanto ao desenvolvimento do comércio eletrônico como canal de comercialização e de comunicação.

\section{Vantagem Competitiva e Estratégias genéricas}

\section{Identificando as Fontes de Vantagem Competitiva}

O cenário contemporâneo impele as empresas a buscarem permanentemente a conquista de vantagem competitiva, ou seja, de posições superiores aos competidores. Um produto ou marca proporciona vantagem competitiva à empresa quando possui características ou atributos que conferem ao produto superioridade sobre os concorrentesimediatos(Lambin, 2000). Essas características diferenciadoras devem constituir um valor para o comprador, em decorrência de custos mais baixos ou de benefícios superiores aos oferecidos pelo competidor. Por outro lado, a superioridade não pode ser interpretada de forma absoluta, mas sim referenciada aos concorrentes prioritários. 
Os diferenciais competitivos podem provir de diversos elementos:

- do produto propriamente dito, incluindo a marca

- dos serviços agregados ao produto;

- de aspectos relativos ao processo produtivo;

- do sistema de distribuição; de condições relacionadas a vendas.

As fontes de superioridade podem ter origem extema ou interna. A vantagem competitiva de origem externa dá ensejo a uma estratégia de diferenciação, a qual permite a obtenção de um preço superior ao do competidor prioritário, em razão da conquista, pela empresa, de um poder de mercado ampliado. A vantagem competitiva de origem interna, por outro lado, fundamenta-se em uma superioridade da empresa em termos de custos de fabricação, de gestão, de administração, de distribuição ou de comunicação, o que permite a obtenção de um custo unitário mais baixo do que o do competidor prioritário. A vantagem competitiva baseada em elementos internos fundamenta-se em maior produtividade e permite que a empresa desenvolva uma estratégia de dominação baseada em custos, como resultado de maior flexibilidade de manipular a variável preço. No entanto, as duas modalidades de conquista de vantagem competitiva podem guardar incompatibilidade entre si (Porter, 1989).

\section{Cinco Forças da Competitividade}

A definição da estratégia competitiva mais adequada dependerá da análise da atratividade da indústria (setor) e da posição competitiva da empresa. A competitividade de uma empresa não decorre apenas de sua posição, relativamente às empresas produtoras dos mesmos produtos ou serviços que oferece, mas também de um conjunto de cinco forças: concorrentes potenciais, fornecedores, clientes, produtos substitutos e rivalidade entre os concorrentes existentes (Porter, 1989).

\section{Estratégias Competitivas Básicas e o Setor de Serviços}

A estratégia competitiva fundamentada na dimensão interna conduz a uma vantagem em custo, enquanto a estratégia com origem na dimensãoexterna lida com preço máximo de venda aceitável (Lambin, 2000).

A escolha da estratégia competitiva poderá apresentar-se segundo uma de três configurações: liderança em custos, diferenciação ou concentração/foco (Porter, 1989). Estas estratégias também podem ser aplicadas às empresas integrantes da indústria de serviços (Fitzsimmons, 1998).

- liderança em custo: uma posição de baixo custo representa uma defesa contra a concorrência, porque os menos eficientes sofrerão primeiro as pressões decorrentes de guerra de preços. A implementação de uma estratégia competitiva baseada em baixo custo requer investimentos em equipamentos, uma política agressiva de preço e aceitação de perdas iniciais para construir participação de mercado;

- diferenciação: a essência da estratégia da diferenciação repousa na criação de um serviço que é percebido como único. Abordagens para diferenciação podem tomar diferentes formas: imagem de marca, tecnologia, características do produto, atendimento ao cliente, rede de distribuição de produtos/seviços e outras dimensões. Uma estratégia de diferenciação não ignora custos, mas sua prioridade é criar a lealdade do consumidor. A estratégia para diferenciar o serviço incorre em custos que o cliente está disposto a pagar;

- foco/concentração: tem objetivo servir muito bem um mercado-alvo específico. A empresa alcança a diferenciação em seu mercado-alvo mediante melhor atendimento às necessidades dos clientes e/ou com o recurso de custos mais baixos.

\section{Riscos das Estratégias Genéricas}

A adoção de uma estratégia genérica possui riscos inerentes que podem eliminar a vantagem competitiva que a empresa obteve inicialmente.

- riscos da estratégia de liderança em custos; podemocorrer mudanças tecnológicas que anulem as vantagens conquistadas. A difusão da tecnologia a baixo custo entre concorrentes é outro elemento que pode eliminar a vantagem obtida. $\mathrm{O}$ foco em custos pode reduzir a capacidade de detectar as mudanças necessárias nos produtos. A ocorrência de inflação de custos também reduz esse diferencial competitivo diante da concorrência;

- riscos da estratégia de diferenciação: o atributo de diferenciação pode conduzir a custos muito elevados, relativamente aos preços praticados no mercado. As necessidades dos consumidores de um produto diferenciado podem diminuir substancialmente ao longo do tempo. Além disso, as imitações costumam reduzir o impacto da diferenciação;

- riscos da estratégia de concentração (foco): o crescimento excessivo do diferencial de preços em relação aos produtos não especializados traz o risco de eliminar a vantagem obtida, ou pode haver diminuição substancial das diferenças entre os segmentos e o mercado mais amplo, dominado por empresas que optam por uma estratégia de cobertura total. Outro risco é a subdivisão do segmento em segmentos ainda menores. 


\section{Condições de Concorrência e Diferenciação}

A estrutura do mercado, como componente de sua atratividade, é elemento fundamental para a escolha da estratégia. Na concorrência perfeita - caracterizada por elevado número de vendedores e compradores e produtos substituíveis e não diferenciados - o preço é um dado e a variável de decisão é a quantidade, pois as empresas não têm oportunidade de construir poder de mercado. Na condição de concorrência imperfeita ou monopolística - grande número de empresas concorrentes e produtos diferenciados - a diferenciação tem por base principalmente as fontes de vantagem competitiva externa, podendo ocorrer mediante nível de qualidade percebida, extensão de serviços oferecidos, rede de distribuição, imagem da marca e outros atributos.

As agências de viagens operam em mercados com características de concorrência monopolística.

Os produtos (no mercado de turismo) não são homogêneos e intercambiáveis, mas diferenciados. Cada empresa vende um produto que, de certo modo, se traduz como único e diferenciado dos demais... (Beni, 1998:145).

O objetivo da diferenciação é elevar o poder de mercado da empresa, decorrente das preferências, da fidelidade dos clientes e da conseqüiente diminuição de sua sensibilidade a preços. O sucesso dessa estratégia implica a diminuição do poder de negociação do cliente e o fortalecimento da empresa contra a pressão da concorrência, em razão da diminuição do grau de substituição do produto ou serviço oferecido.

Algumas estratégias de diferenciação são possíveis pela obtenção de alta qualidade ao lado de uma política de marca, incorporação de avanço tecnológico reconhecido, melhoria do serviço de pós-venda, integração de atividades de alto valor agregado etc. (Levitt, 1980). A diferenciação protege a empresa das forças competitivas de várias maneiras:

- dos concorrentes diretos: pelo aumento da fidelidade e consequiente diminuição da sensibilidade a preços;

- de novos concorrentes: a entrada de novos concorrentes é dificultada pela maior fidelidade do cliente;

- do poder de barganha dos fornecedores: a maior lucratividade torna a empresa mais resistente a eventuais restrições por parte dos fornecedores;

- do poder de barganha dos clientes: a diferenciação permite o aumento do poder de mercado da empresa e os consumidores tornam-se menos sensíveis a preços;

- ameaça de produtos substitutos: a maior fidelidade dos clientes, ao lado de atributos mais valorizados do produto, tornam-no menos suscetível a substituições.
Como resultado, a empresa tenderá a criar um ambiente de concorrência monopolística (Chamberlin, 1950).

\section{Diferenciaçāo para o Distribuidor de Serviços}

Diversos elementos auxiliam a ilustrar as possibilidades de diferenciação que se abrem à empresa distribuidora de serviços.

\section{Caracteristicas dos Consumidores}

Uma das formas de avaliar as fontes geradoras de valor é a identificação dos atributos de produto requeridos pelos consumidores.

É oportuno, primeiramente, apontar algumas características do "novo consumidor". Uma das mudanças mais significativas no mercado foi o surgimento do consumidor informado (Wortzel, 1987). Ele é capaz de comparar e escolher, abstraindo-se de marcas, da propaganda ou de argumentos, no decorrer do processo de compra, e pode distinguir as características dos produtos e serviços que aumentam o valor do produto. $\mathrm{O}$ consumidor procura pesquisar e comprar com a maior eficiência possível, buscando acesso ao maior número de opções disponíveis. Há, ainda, aqueles consumidores que preferem agregar diversão e oportunidade de interação social às suas compras (Forman e Sriram, 1991).

\section{Tipologia dos Produtos de Consumo}

O produto turístico destinado ao consumo final pode ser considerado um conjunto de diversos serviços singulares, podendo ser composto pelo próprio consumidor (Beni, 1998). Quando o consumidor compra serviços em uma agência de viagens, ele realiza pagamentos prévios e/ou assume uma dívida, em um momento que antecede o consumo efetivo que ocorrerá somente no destino, fazendo com que os atributos de segurança e confiança tenham alta relevância nas transações com as agências de viagens.

A valorização dos produtos por parte do consumidor, isto é, como ele percebe valor nos produtos que adquire, segundo afirma Lambin (2000), é distinta, conforme a categoria do produto. Nesse aspecto, os produtos podem ser classificados em três categorias:

- produtos de compra corrente (comportamento de compra rotineiro): produtos de primeira necessidade e de compra impulsiva; 
- produtos de compra com urgência: compra inadiável;

- produtos de compra reflexiva (produtos de risco percebido médio): na compra reflexiva, o consumidor compara marcas segundo atributos como o grau de adaptação ao uso previsto, estética, preço, qualidade. Essa modalidade costuma envolver itens com preços elevados e baixa freqüência de compra. Viagens e os serviços complementares, em muitos casos, são adquiridos mediante comportamento semelhante. As informações e orientações/aconselhamentos do agente de viagens são, em boa parte dos casos, decisivas para a realização da compra.

As compras reflexivas podem ser alimentadas por diferentes tipos de informações (Peterson et al., 1997). Em um extremo encontram-se as compras que necessitam de pesquisas e informações externas sobre o produto ou o serviço; no outro, estão as compras de produtos que são adquiridos mediante inspeção ou experimentação pessoal. No caso de bens que necessitam de informações externas, "bens de conhecimento", cujas informações podem ser objetivamente transmitidas, a internet poderá ser um meio adequado de realização de funções de transação e comunicação, podendo prescindir de intermediários. Com os bens de experimentação pessoal, a substituição do intermediário será dificultada. No entanto, o consumidor pode experimentá-lo junto ao intermediário e depois recorrer ao canal de venda direta que utilize a internet, efetivando aí a compra. Os bens de experimentação que fazem parte do consumo rotineiro poderão ter na internet um meio de realização de funções de transação, abrindo a possibilidade de prescindir do intermediário.

Além da polarização conhecimento-experimentação, os bens podem ser classificados de acordo com outras dimensões relevantes (Peterson et al., 1997):

- preço em associação com freqüência de compra: em um extremo estão agrupados produtos de baixo preço e compra freqüente e, no outro, produtos de alto preço e compras pouco freqüentes;

- proposta de valor: se o produto étangívele físico, ou se é intangível ou relacionado a serviços;

- grau de diferenciação: refere-se ao grau de percepção do produto, pelos consumidores, como uma commodity, ou, alternativamente, como um produto diferenciado.

\section{Atributos para as Compras}

Sob a perspectiva do consumidor, o ponto-de-venda pode ser descrito a partir da consideração de alguns atributos, cuja importância varia segundo as características de comportamento desse consumidor. No caso de prestação de serviços, pode haver critérios específicos para avaliação e seleção do ponto-de-venda pelo cliente em potencial, como conveniência e preço. Além desses, os seguintes critérios podem ser apontados, dependendo da concorrência e das necessidades específicas do cliente (Fitzsimmons, 1998): disponibilidade, confiança, personalização (customização), qualidade, segurança e presteza. Da mesma forma, as compras em agências de viagens podem ser avaliadas de acordo com atributos particulares, como proximidade, segurança, variedade, facilidades, aconselhamento (Machín, 1993).

A Tabela 1 resume os principais atributos, sob o ângulo do consumidor, relativos ao varejo, aos serviços e, especificamente, às agências de viagens, os quais podem constituir fontes geradoras de valor.

\section{TABELA 1 - ATRIBUTOS DA OFERTA COMO FONTE GERADORA}

\section{DE VALOR}

\begin{tabular}{l|l|l}
\hline \multicolumn{1}{|c|}{ VAREJO } & \multicolumn{1}{|c|}{ SERVIÇO } & AGÉNCIA DE VIAGEM \\
\hline $\begin{array}{l}\text { Converiência/ } \\
\text { proxinidade } \\
\text { Sortimento }\end{array}$ & $\begin{array}{l}\text { Converiência/ } \\
\text { proxinidade }\end{array}$ & Converiência/proximidade \\
Preço & $\begin{array}{l}\text { Preço } \\
\text { Segurança } \\
\text { Disponibilidade }\end{array}$ & Sortimento \\
Serviço & $\begin{array}{l}\text { Senfianç̧a } \\
\text { Tempo }\end{array}$ & \\
Ambiente & Personalização & Facilidade \\
& Qualidade & Aconselhamento \\
\hline
\end{tabular}

Fontes: Lambin (2000); Fitzsimmons (1998); Machin (1993).

No caso das agências de viagens, é importante tecer alguns comentários sobre os atributos que lhe são próprios.

\section{Conveniência/proximidade}

A localização define a conveniência para os consumidores que se deslocarão para o serviço. Posto de gasolina, conjugado com caixa automático, loja de conveniência, drogaria e borracheiroé um exemplo de ilha de serviços localizada em avenidas de grandes centros urbanos. 


\section{Sortimento}

O sortimento refere-se à variedade de produtos, em termos de amplitude variedade de funções, de longitude; variedade de modelos dentro de uma mesma função -, e de profundidade - variedade do número de referências por modelo dentro de uma mesma função.

\section{Segurança}

Bem-estare segurança são atributos importantes, porque em muitos serviços, tais como transporte aéreo e medicina, os consumidores estão colocando as suas vidas nas mãos dos prestadores de serviço.

\section{Facilidades}

A realização de uma viagem pode apresentar diversas barreiras, como a língua, a burocracia, o conhecimento da qualidade e dos preços relativos dos serviços em locais distantes, a necessidade de ter que adquirir diversos tipos de serviços complementares. O fornecimento dos serviços de viagens desprovidos dessas barreiras é visto como um valor.

\section{Aconselhamento}

A possibilidade de receber ajuda na decisão de certos tipos de compra, como viagens, é vista como um valor por certa parcela de consumidores. O produto turístico é formado por um conjunto de serviços cujas características não são evidentes para o comprador. Assim sendo, ele só pode ser inspecionado no destino, depois de comprado, carecendo, pois, de aconselhamento para que seja devidamente comercializado.

\section{Elos Verticais e Geração de Valor na Indústria Turistica}

Finalmente devem ser lembrados os elos verticais na geração de valor na indústria turística. A cadeia de valor é uma ferramenta analítica que pode ser utilizada para analisar o processo de criação de valor na indústria turística e a intensificação da vantagem competitiva.
As atividades primárias, essenciais na operação de um empreendimento na indústria turística, são transporte, serviços no local, atacado/pacotes, marketing, distribuição no varejo, vendas, serviços ao cliente. As atividades de apoio consistem na infra-estrutura essencial de um empreendimento. Na indústria de turismo, tais atividades não diferem substancialmente daquelas encontradas em outras indústrias, e incluem infra-estrutura da empresa, recursos humanos, desenvolvimento de produtos e serviços, desenvolvimento de tecnologias e sistemas e aquisição de bens e serviços.

\section{Ambiente de Marketing na Indústria Turística}

As variáveis pertinentes ao ambiente externo, compreendendo forças não controláveis, definem as tendências do setor, as oportunidades de marketing e as ameaças decorrentes de mudanças nesse ambiente. $\mathrm{O}$ ambiente da indústria do turismo é retratado por Beni (1998), conforme exibido na figura 1.

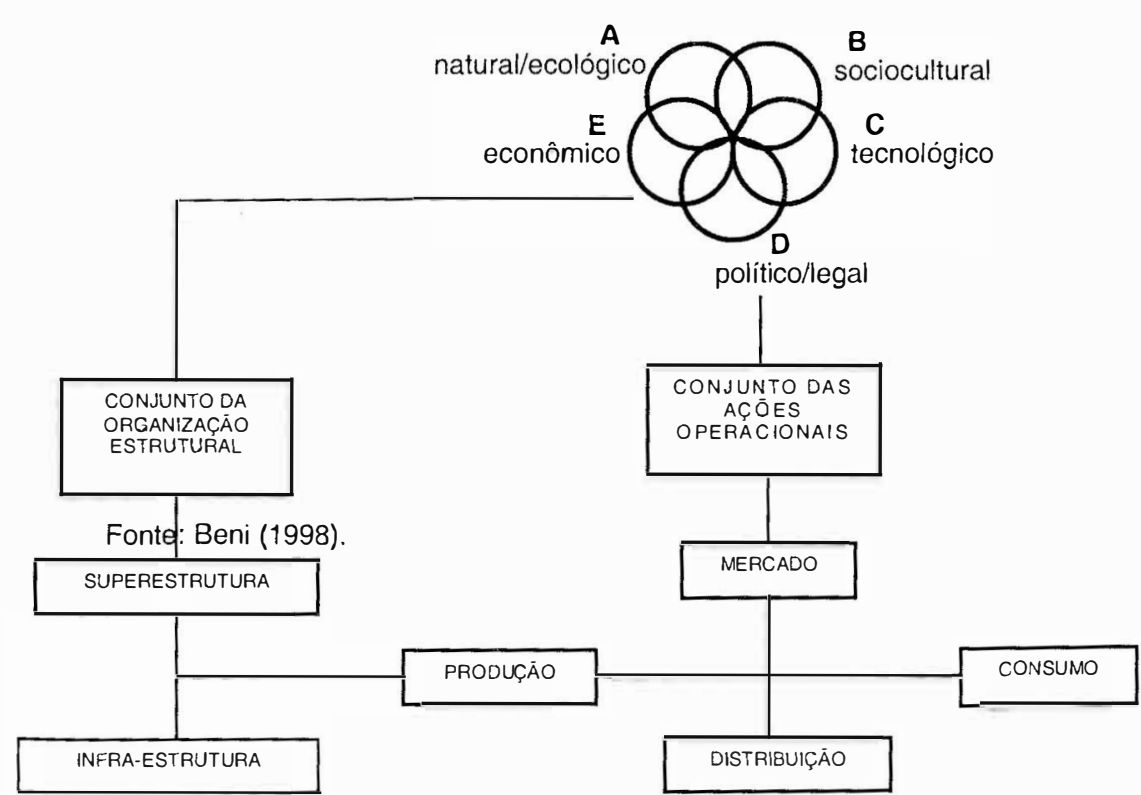

FIGURA 1 - CONJUNTO DAS RELAÇÕES AMBIENTAIS

O "conjunto da organização estrutural" abrange a "superestrutura" a "infraestrutura". A superestrutura engloba a organização político-institucional relacionada às ações governamentais. A infra-estrutura pode ser geral ou específica. A primeira atende a todos os setores econômicos e à população como um todo. O 
turismo é beneficiado por sua presença. Ela refere-se a equipamentos e serviços correlatos, ligados a saneamento básico, transporte, energia, comunicações, segurança, funções sociais. A infra-estrutura específica, por sua vez, atende às mesmas funções, porém focam as necessidades turísticas. O"conjuntodas relações ambientais" diz respeito a aspectos do macroambiente: demográficos, econômicos, físicos, tecnológicos, político-legais e socioculturais. O "conjunto das ações operacionais" vincula-se à produção, consumo, distribuição, envolvendo os agentes do "ambiente imediato" da empresa, ou seja, a própria empresa, fornecedores, intermediários, clientes, concorrentes. A esses agentes podem ser acrescidos os stakeholders, aqueles que têm algum interesse nas atividades da empresa.

A produção no turismo traduz-se em transporte, alojamento, outros serviços e inclui o agente de viagens. As agências de viagens vendem serviços de transporte, de alojamento, de entretenimento, entre outros, cada um dos quais de forma separada ou, alternativamente, integrando um composto ou pacote de serviços. Os fornecedores das agências de viagens são as empresas aéreas, as locadoras, os hotéis etc. Essas empresas fornecem os insumos para que as agências componham os "pacotes" de serviços. As agências de viagens podem ter as operadoras como fornecedoras de pacotes previamente formatados.

No fornecimento desses produtos, os "canais de distribuição" são fundamentais, porque os produtos da indústria do turismo, conforme já lembrado, não podem ser inspecionados por ocasião da comercialização, mas apenas nos destinos, depois de realizada a venda.

Os agentes de viagem e os operadores desempenham a principal função de distribuição na indústria do turismo, muito embora companhias aéreas e outros fornecedores possam vender diretamente aos passageiros e turistas. Agentes atendem às necessidades dos visitantes e asseguram que as operadoras concretizem a promessa registrada em seus catálogos de viagem. A agência de viagem exerce um papel de varejista (Ikeda, 1993). Em parte, desempenham também a função de produtor e comercializam a produção. Para o comprador de produtos turísticos, a obtenção de informações e de aconselhamento são dois dos aspectos mais valorizados. A falta desses aspectos pode fazer com que compradores potenciais procurem por outros canais de venda.

\section{Distribuição de Produtos Turísticos}

A distribuição de produtos turísticos apresenta diferentes aspectos, os quais serão descritos resumidamente.
Papel da Distribuição sob a Ótica Econômica

Um canal de distribuição pode ser definido como uma estrutura pae participa do intercâmbio competitivo, com o objetivode colocar bens ou serviços à disposição dos consumidores (Lambin, 2000). Essa estrutura pode ser formada por produtores, intermediários e consumidores. A distribuição tem por objetivo diminuir as disparidades existentes entre produção e consumo, em relação a locais, ocasiões e configurações, criando valor pela entrega das utilidades de lugar, de tempo e de forma.

\section{Função da Distribuição}

A função da distribuição diz respeito ao desempenho de um conjunto de atividades voltados a transportar, fracionar, armazenar, criar sortimento, estabelecer contato e informar. Além disso, o intermediário pode agregar serviços, tirando proveito de sua maior proximidade com o consumidor.

\section{Configuraçôes de um Canal de Distribuição}

O canal de distribuição pode ser direto ou indireto. O primeiro é o que liga diretamente o produtor ao consumidor; o segundo conta com a participação de um ou mais intermediários. O produtor pode comercializar seus produtos utilizando as duas modalidades de canal.

\section{Concorrência entre Distribuidores}

A concorrência entre distribuidores ocorre de quatro maneiras (Lambin, 2000):

- horizontal: concorrência entre intermediários de mesmo nível funcional;

- horizontal intertipos: concorrência entre intermediários situados no mesmo nível da rede de distribuição, mas que utilizam formas distintas de venda; por exemplo, atendimento pessoal ou atendimento online;

- vertical: intermediários situados em diferentes níveis da rede de distribuição, mas que exercem funções semelhantes, "à montante" ou "à jusante" de sua localização original;

- entre redes de distribuição: redes inteiras concorrendo entre si. 
Tradicionalmente, os intermediários têm desempenhado um importante papel, em virtude das distâncias geográficas e das dificuldades de se alcançarem todos os segmentos. A expansão da internet como canal de comercialização reduz a importância da distância geográfica e de aspectos que, nos canais tradicionais, estimulam a diferenciação e diminuem os efeitos da concorrência.

Uma forma de enfocar os canais de distribuição do produto é agrupar as necessidades turísticas em confronto com as empresas que podem satisfazê-las. De acordo com Krippendorf apud Beni (1998), os principais grupos de necessidades turísticas são deslocamento, alojamento, alimentação, recreação e entretenimento, saúde, convalescença e restabelecimento, informação e organização de viagens.

As necessidades que os turistas têm de informação e de organização de viagens podem ser supridas por dois tipos de empresas: as operadoras de turismo e as agências de viagens. As operadoras de turismo realizam as necessárias reservas de hotéis, passagens de avião, por exemplo, para oferecer compostos de viagens ou "pacotes". As agências de viagens vendem esses pacotes no varejo. Realizam também reservas de transporte e de alojamento, de acordo com os pedidos dos turistas (Beni, 1998).

\section{Ambiente Competitivo na Indústria Turistica}

As forças competitivas que moldam o ambiente de negócios na indústria turística são um elemento indispensável de análise pelas empresas que operam no setor. A seguir serão feitos alguns comentários concernentes a essas forças.

\section{Concorrentes Potenciais}

Com referência aos concorrentes potenciais, pode se afirmar que a existência de barreiras à entrada é um fator que determina o grau de competição na indústria. $\mathrm{O}$ segmento das agências de viagens apresenta fracas barreiras de entrada. A quantidade de agências experimentou forte aumento após a remoção de fatores legais restritivos e a estabilização da moeda em 1994.

\section{Fornecedores e Clientes}

O desenvolvimento da rede pode repercutir sobre o poder de negociação dos fornecedores, de um lado, e dos clientes, de outro. Os fornecedores passam a contar com um poderoso instrumento para atingirem seus clientes por meio de um canal direto de distribuição.

\section{Integração Vertical da Distribuição}

A importância da atividade de agenciamento, ao lado da estrutura oligopolista dos transportadores aéreos e marítimos, coloca em discussão a possibilidade de crescimento da integração vertical da distribuição. As companhias aéreas geralmente vendem bilhetes diretamente aos passageiros. Segundo Beni (1998), no Brasil, as agências de viagens respondem por cerca de $75 \%$ do volume de vendas de passagens aéreas. Os hotéis, também, realizam vendas diretas, possuindo, em alguns casos, representantes ou centrais de reservas. Com a rede, os clientes passam a contar com um instrumento que os auxilia na obtenção de informações e na possibilidade de realizar comparações de forma objetiva. As possibilidades de distribuição direta passam a ser maiores.

\section{Substituição de Produtos/Fornecimento Substituto}

Na base de atuação das agências de viagens está o tipo da compra realizada. As compras, como já mencionado, são predominantemente reflexivas. No caso da necessidade de informações objetivas, que complementem viagens a locais já experimentados e conhecidos pelo usuário, e/ou que ofereçam serviços confiáveis, sem que haja prévia experimentação-destinos tradicionais, não exóticos - a internet pode substituir um intermediário, ou uma agência poderá substituir outra, se conseguir agregar valor suficiente. No caso de bens de experimentação pessoal destinos exóticos, destinos pouco freqüentados - a substituição do intermediário será mais difícil. Destinos caracteristicamente de experimentação, mas que façam parte do consumo rotineiro de uma parcela dos consumidores, no entanto, são mais susceptíveis a mudanças de fornecedor ou de canal de comercialização.

\section{Aspectos do Ambiente Econômico}

O movimento de passageiros internacionais subiu de 69 milhões, em 1960, para mais de 500 milhões, em meados dos anos 90. O setor, compreendendo atividades de hospedagem, transporte, agenciamento de viagens, organização de eventos e congressos, promoção de atrações e locação de automóveis, responde por parcela significativa do PIB e do emprego mundiais. Os resultados gerados pelo turismo internacional saltaram de US $\$ 6,9$ bilhões, em 1960, para mais de US $\$ 300$ bilhões, em 1994 (OMT, 1997). Este valor é superior à receita com exportações mundiais de petróleo, veículos automotivos e equipamentos eletrônicos. A crescente integração internacional, sob efeito da globalização, afetou positivamente os fluxos turísticos internacionais. 
Em 1991, nos EUA, a arrecadação das agências de turismo atingiu a cifra de US $\$ 85,9$ bilhões. As viagens domésticas responderam por $69 \%$ desse total e as internacionais por $31 \%$. Após a desregulamentação do setor de turismo, ocorrida em 1978, o número de agências de viagens nos Estados Unidos passou de 14.804 para 32.066. A maioria das agências está automatizada. Em 1989, 95\% das agências estavam automatizadas, enquanto, em 1981, esse número era de apenas 69\% (ABAV, 1996)

No Brasil, entre 1991 e 1993, o número de agências com produção aérea internacional cresceu de 4.504 para 5.340 e, nas dedicadas à venda de passagens nacionais, o número evoluiu de 3.355 para 4.198 (ABAV, 1996). Para parcela significativa das agências, a venda de bilhetes aéreos é a atividade preponderante.

Por outro lado, o setor ocupava diretamente mais de 150 mil pessoas, assim distribuídas: 38.123 empregados fixos, 9.901 sócios proprietários e 5.842 free lances. Pode-se destacar, no Brasil, a tendência à concentração de vendas de passagens aéreas para viagens internacionais, ao contrário do que se verifica, por exemplo, nos Estados Unidos.

\section{Aspectos Tecnológicos}

O acervo de definições para o termo tecnologia é amplo. A convergência de opiniões de diferentes autores conduz à seguinte consideração: tecnologia é, antes de tudo, conhecimento e, mais especificamente, conhecimento útil aplicado às atividades humanas, especialmente, mas não exclusivamente, àquelas ligadas aos processos de produção, distribuição e utilização de bens e serviços (Rosenthal, 1992). Outrossim, tecnologia abrange não apenas os conhecimentos científicos, mas também aqueles adquiridos e acumulados por meio do próprio exercício da atividade à qual especificamente diz respeito.

Cabe, ainda, um comentário relativo à questão da inovação tecnológica. A palavra inovação apresenta múltiplas acepções, conforme a área de estudo ou a tradição de pesquisa que a utiliza. Em marketing, inovação pode ser qualquer modificação percebida pelo usuário, mesmo que não ocorra nenhuma alteração física no produto. Na área de produção/operações, inovação é a introdução de novidades materializadas em produtos, processos e serviços novos ou modificados (Barbieri, 1997). formas:

Convém salientar que as inovações podem se apresentar sob diferentes

- novo processo produtivo ou alteração do processo existente, com o objetivo de reduzir custos, melhorar a qualidade ou aumentar a capacidade de produção;

- modificações no produto existente ou a substituição de um modelo por outro, que cumpra a mesma finalidade básica, muitas vezes acrescida de outras complementares;
- introdução de no

fabricados a partir de um processo produtıvo comum ou afim;

- introdução de novos produtos que exigem novas tecnologias da empresa.

Rosenthal (1992) destaca alguns elementos indicativos da importância da tecnologia e da inovação tecnológica como base de vantagem competitiva:

- diferentes tecnologias utilizadas para um fim mais ou menos genérico têm, em geral, diferentes níveis de eficácia e/ou eficiência, embora, muitas vezes, se possa identificar a ocorrência de trade-off, no que se refere às propriedades específicas dos bens produzidos e/ou aos custos de produção associados a determinada tecnologia;

- em um mesmo mercado, diferentes tecnologias podem levar a diferentes resultados (desempenho) das empresas que nele atuam - seja em termos de níveis de qualidade e/ou desempenho de um mesmo tipo de produto (do ponto de vista de durabilidade, confiabilidade, beleza etc.), da eficiência do processo produtivo (que se reflete diretamente nos custos de produção) ou, ainda, da natureza intrínseca do produto (meio para solucionar problemas e/ou atender a necessidades ou desejos do mercado);

- a introdução de inovações tecnológicas constitui um dos principais instrumentos de concorrência no sistema capitalista. O esforço compulsivo dos empresários busca consolidar ou melhorar sua posição no mercado, pela introdução de inovações no processo produtivo, seja para produzir novos ou melhores produtos, seja para ampliar as escalas de produção e/ou reduzir os custos;

- o sucesso de uma empresa, ou, em outros termos, seu grau de competitividade, depende de sua capacidade de oferecer produtos passíveis de serem vendidos a preços que assegurem a empresa lucros mais elevados, tendo por limite inferior seus custos de produção (no sentido mais amplo) e, por parâmetro de aferição, a taxa média de lucro do setor;

- a tecnologia - tomada em seu sentido mais amplo, abrangendo o conjunto de conhecimentos utilizados não apenas na fabricação, mas em todo o processo de interação da empresa com seu ambiente - constitui um dos instrumentos determinantes na avaliação do grau de competitividade de uma empresa.

No campo dos serviços, "o processo é o produto", porque os consumidores participam diretamente das ações que envolvem a entrega do serviço (Fitzsimmons, 1998). Consequentemente, o sucesso da inovação tecnológica, particularmente nas atividades de linha de frente ${ }^{4}$, depende da aceitação do consumidor. O impacto nos consumidores não é somente limitado à perda da atenção pessoal no atendimento. Eles também precisam aprender a operar novas tecnologias e a lidar com novas estruturas; por exemplo, como operar um caixa automático ou uma bomba de

4. Serāo usados os termos linha de frente e retaguarda para designar, respectivamente, front office e back office, termos adotados por Christopher Lovelock (1991). 
gasolina. A contribuição dos consumidores no processo de produção, como participantes ativos ou co-produtores, pode ser considerada na ocorrência de mudanças no sistema de entrega do serviço.

Inovação na retaguarda, a qual não está diretamente ligada ao consumidor, pode trazer outros tipos de implicações. A retaguarda é o ambiente mais propício para a introdução da automação nos serviços, porque as operações que lhe estão afetas frequientemente são repetitivas e rotineiras e, consequentemente, apropriadas para a introdução de dispositivos de economia de trabalho.

Outro aspecto digno de nota é a tecnologia da informação, operando em tempo real, com foco nas operações internas, a qual pode desempenhar um papel impulsor das condições competitivas, propiciando a oportunidade de melhoria de receita. $\mathrm{O}$ banco de dados de uma empresa de serviços pode ser um ativo oculto de importância estratégica. Os custos para construir e manter um grande banco de dados já é em si uma barreira de entrada para os concorrentes.

A informatização é vital para vários setores da economia, incluindo o setor de viagens. A evolução da informática no setor de telecomunicações atribuiu maior eficiência às operações na indústria, principalmente nos setores de venda e gestão. A maior eficiência operacional está associada, no entanto, ao surgimento de ameaças para as agências de viagens. Com o acesso mais amplo à informação por meio dos recursos da informática e da internet, os clientes poderão fazer suas reservas diretamente junto aos fornecedores, sem a utilização de uma agência como intermediário. As tendênciasainda nãoestão claramente delineadas. As mudanças tecnológicas em curso são responsáveis por oportunidades e ameaças geradas para o setor. Embora alguns fatores possam contribuir para a redução do número de viagens, a expansão do setor de turismo no mundo tende a ter continuidade. A aceleração do processo de globalização, embora envolvendo a rápida circulação de informação, envolve também maior circulação de pessoas. A elevação da renda mundial, mesmo que lenta, tem impactos positivos mais que proporcionais nas viagens.

\section{Comércio Eletrônico}

Aqueles que puderem administrar sua cadeia de valor e alcançar vantagem competitiva estarão bem posicionados para aproveitar as oportunidades proporcionadas pelo ambiente (Kavanagh, 1999). Especificamente quanto ao comércio eletrônico e suas variantes - business-to-business, e-business e outros -, a questão é se este é um caminho para gerar novos negócios, ou apenas uma forma de obter uma vantagem de custo em negócios tradicionais. Ambos são igualmente valiosos, porém, na primeira hipótese, não se estaria focando a geração de novos negócios, mas transferindo negócios de outro canal para a internet.

Toledo et al. (1996) sugerem um modelo de varejo, configurando uma nova estrutura de empresa de varejo virtual e redefinindo alguns elementos do sistema como o perfil do funcionário, o valor do tempo, a informação e a comunicação, os métodos de distribuição e até mesmo o conceito de gerência. Destaque se dê para o valor do tempo e o valor da informação no comércio eletrônico pela internet. O primeiro refere-se a uma redução do período de tempo entre a solicitação do bem (produto ou serviço) e a entrega do mesmo. Empresas baseiam seu diferencial nos fatores tempo e flexibilização na produção, mantendo a concorrência à distância com uma produção "virtualizada" de alta velocidade. Já a informação constitui, por si só, o diferencial que faz as empresas saírem na frente e manterem-se em vantagem. Sua obtenção e o uso correto dela levam empresas similares e concorrentes a se distinguirem e se distanciarem em virtude da vantagem competitiva conseguida por uma delas.

As formas de comercialização se alterarão com o uso ampliado do varejo virtual, em que o cliente é cadastrado, considerando-se sua organização e operações habituais de compra, suas preferências, hábitos de compra, data das últimas aquisições, tipo de produto procurado, estilo de vida, personalidade, renda e demais fatores que permitam traçar o perfil de seu comportamento de compra. A partir daí lhe são sugeridas e comunicadas opções de produtos ou serviços de forma individualizada e na ocasião em que forem requeridos.

\section{Novos Paradigmas na Relação Empresa-Consumidor}

A internet propicia às empresas, novas maneiras de criar relações com o consumidor e construir as vendas. Internet oferece uma abundância de benefícios que, a longo prazo, reduzirão os custos de vendas e poderão reforçar os lucros das empresas usuárias, por meio de, por exemplo (Garner, 1999):

- construção de lealdade do consumidor: um site que oferece serviços não encontrados em um concorrente faz com que o visitante retorne a ele;

- redução de custos operacionais: pedidos on line e seu acompanhamento reduzem o custo de processamento da transação do consumidor;

- aceleração do processo de venda: os sites eletrônicos oferecem a conveniência, a simplicidade e a prontidão demandadas pelos consumidores;

- melhoria do relacionamento: sites comerciais de sucesso antecipam-se aos problemas rotineiros do consumidor, permitindo que o vendedor concentre-se em aspectos que forjarão uma forte ligação entre ele e o cliente, permitindo que o vendedor concentre-se em assuntos estratégicos que forjarão uma forte ligação entre o vendedor/consumidor;

- redução dos custos de venda: a equipe de venda pode dispensar mais tempo com vendas e responder a dúvidas e perguntas dos clientes. 


\section{Tendências do Mercado Eletrônico}

A internet pode ser vista como uma descontinuidade quanto à visão que se possui do mercado (Peterson et al., 1997). Isto porque não se pode prever, com clareza, seus impactos, especialmente em virtude da velocidade das mudanças e da imprevisibilidade do comportamento do consumidor. Alguns aspectos auxiliam a compreender os possíveis impactos sobre o consumo e, em consequiência, podem clarear o processo de adoção de decisões estratégicas. Nesse sentido, pelo menos quatro pressupostos são relevantes (Peterson et al., 1997):

- poderá ocorrer a "universalização do consumo" pela internet, entendida como a compra de pelo menos um tipo de produto ou serviço por essa via, pela maioria dos consumidores. Isto poderá ser mais verdadeiro para os EUA, mas deve ser considerado como possibilidade para os consumidores de alto e médio poder aquisitivo dos demais países, do Brasil inclusive;

- a universalização não deverá ser acompanhada de crescimento nas despesas de consumo, ou seja, haverá uma migração de parte do consumo, que virá de outros canais;

- as inovações tecnológicas na infra-estrutura e nas várias formas de acesso, que acompanham o desenvolvimento da internet, das mais triviais às que ainda não estão disponíveis - cabos de comunicação exclusivos, TV a cabo, linhas telefônicas, comunicações via satélite, complementados por acesso por monitores de TV, computadores pessoais, aparelhos de reconhecimento de voz-, não deverão afetar o conteúdo de seus impactos mais gerais sobre o consumo;

- a questão da segurança e privacidade deverá encontrar soluções aceitáveis, considerando a longo prazo, podendo ficar entre alternativas como o e-cash criptografia e outros artifícios.

De forma geral, deve ser ressaltada a existência de um certo grau de substituição entre a comercialização via internet e as formas convencionais, bem como sua complementaridade, o que conduz a possibilidades de sinergia entre os distintos tipos de canais.

Como canal de marketing, a internet possui características próprias, das quais podem ser citadas as seguintes:

- armazenagem a baixo custo de vasta quantidade de informações;

- disponibilidade de poderosos meios de pesquisa, organização das informações e disseminação;

- interatividade e capacidade de fornecer as informações demandadas;

- capacidade de proporcionar experiências de percepção superiores às proporcionadas por catálogos impressos, porém inferiores às obtidas diretamente por contato pessoal;

- capacidade de processar transações;
- capacidade de ser um meio de distribuição física para certos bens como softwares; - baixos custos de entrada para fornecedores de bens e serviços.

Conforme já observado, os serviços e produtos podem variar de acordo com o tipo de informação necessária para sua compra, estando em um extremo aqueles que necessitam de pesquisas e informações externas ao produto ou serviço e, em outro, os que são comprados mediante inspeção ou experimentação pessoal. Para os bens de experimentação, caracteristicamente de consumo rotineiro, pode-se recorrer à internet como meio adequado de realização de funções de comunicação e de transação.

De acordo com Peterson et al. (1997), produtos intangíveis apresentam boa adaptabilidade ao uso da internet como canal de transação, o mesmo ocorrendo com as viagens. Portanto, a ameaça para essas últimas parece clara: seus fornecedores podem converter-se em seus principais concorrentes. O extremo de adaptação seria, por exemplo, a compra de viagens aéreas para locais já conhecidos. Nos EUA, as empresas aéreas têm aumentado significativamente sua participação nas vendas. Por terem seus processos operativos já adaptados à internet podem prescindir do intermediário, dependendo, naturalmente, de outros fatores condicionantes. Naquele país, o comércio eletrônico registra cerca de 10 milhões de pessoas, do total de 60 milhões de usuários da rede, que já fizeram compra online, tendo movimentado, em 1998, algo em torno de US\$ 6 bilhões (Nielsen Media..., 1998). No Brasil, o comércio eletrônico está apenas iniciando, e as cifras ainda são modestas.

Pesquisa realizada em 1998, apontou que foram movimentados na rede US $\$ 14$ bilhões nos EUA, contra apenas US\$167 milhões em toda a América Latina (US $\$ 77$ milhões referentes a empresas sediadas na região e US $\$ 90$ milhões gastos em sites baseados nos EUA). Segundo o mesmo estudo, em 1997, no Brasil, 1,2 milhão de usuários estavam ligados à rede, elevando-se essa cifra para 2,7 milhões, em 1998, e superando 4 milhões, em 1999 (Visa, 1998).

De acordo com esse cenário, a indústria de viagem e turismo apresenta números específicos. Segundo a Travel Industry Association (1999), em 1997, 6,7 milhões de turistas fizeram suas reservas online, nos EUA, um crescimento de $11 \%$ sobre o ano anterior. Este número inclui reservas e/ou pagamentos de bilhetes aéreos, hotéis, locação de automóveis etc. $\mathrm{O}$ percentual de turistas usuários de serviços online destinados a traçar planos de viagens e/ou realizar reservas cresceu de $11 \%$, em 1996, para 28\%, em 1997. Ao mesmo tempo, houve crescimento de $19 \%$ entre os que preferem realizar reservas via internet a utilizar uma agência de viagens. Em 1998, o número de turistas que fizeram suas reservas pela internet foi estimado em 12,1 milhões de pessoas. As receitas online do setor turístico, por outro lado, evoluíram de US $\$ 276$ milhões, em 1996, para US $\$ 1$,9 bilhão em 1998. É previsto o valor de US $\$ 8,9$ bilhões para 2002, quando 72 milhões de pessoas poderão fazer compras de viagens recorrendo à rede. 


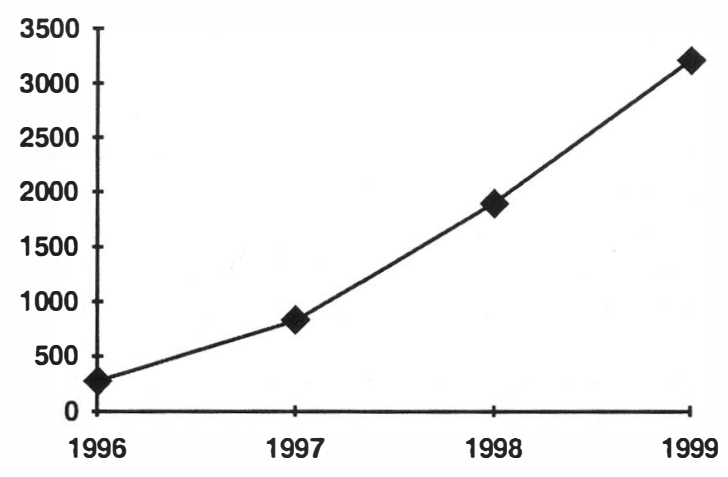

Fonte: Travel Industry Association of America (1999).

\section{FIGURA 2 - RECEITAS DE SERVICOS TURISTICOS ONLINE - EUA (CÁLCULOS E PROJEÇÕES EM US\$ MILHÕES)}

\section{Estudo de Caso}

\section{Aspectos Metodológicos}

Para ilustrar as questões discutidas conceitualmente, optou-se pela apresentação de um estudo de caso, mediante uma abordagem exploratória.

Segundo Parasuraman (1991), o estudo exploratório tem por objetivo fornecer pistas e indicações sobre um tema em exame e apresentar direções para investigações posteriores. Os estudos exploratórios podem ter por base uma amostra pequena e ser realizados mediante uma coleta de dados flexível. A análise dos dados pode ser informal e não quantitativa e as inferências e recomendações têm caráter não conclusivo. As análises exploratórias podem ser conduzidas por meio de estudo de caso, o qual se direciona ao exame de uma unidade de interesse, dentro do universo mais amplo. Muitas vezes, a informação procurada não é completa, situação que pode ensejar a utilização de um estudo de caso, a partir do qual deverão ser obtidas pistas e idéias para pesquisas posteriores, com escopo mais abrangente.

Os estudos de caso podem ser exploratórios, descritivos ou explanatórios (Yin, 1990). Podem lidar com documentos ou entrevistas e observações, mas não permitem generalizações para o universo em estudo, já que lida com amostra intencional e, portanto, não-probabilística. Eles possibilitam, no entanto, a verificação da consistência de conceitos a situações específicas. Com isso, obtém-se a confirmação de elementos da teoria em relação a parcelas significativas da população.
Foram estudados, mediante o método acima descrito, duas agências de viagens e investigados aspectos diversos como posturas e expectativas adotadas diante de preços, custos, imagem da marca, personalização dos serviços e fidelização.

\section{Sintese dos Resultados do Estudo}

Foram selecionadas duas agências, que utilizam a internet com o propósito de divulgar seus serviços: uma dedicada ao business-to-business e a outra ao público em geral.

\section{Perfil das Empresas}

A agência de viagens "J" atende às pessoas jurídicas em suas necessidades de viagens emissoras ou receptivas de negócios. As viagens motivadas por negócios podem gerar, de forma subsidiária, turismo de lazer. Boa parte dos serviços comercializados pode ser classificada como "bens de conhecimento", ou seja, aqueles que demandam informações objetivas para serem adquiridos. A agência atende cerca de 2 mil turistas por ano.

A segunda agência de viagens, designada por "P", atende ao público em geral, ou seja, pessoas físicas em busca de lazer. É uma empresa dedicada à venda de pacotes personalizados para destino exótico, na América do Sul. Seu core business é constituído por um "bem de experimentação", que, no caso de viagens, pode ser entendido como um "bem de aconselhamento", ou seja, aquele que só pode ser comprado se acompanhado de informações detalhadas e orientação por profissionais de alta confiabilidade, já que viagens só podem ser inspecionadas no destino. Essa agência atende cerca de 200 turistas por ano.

\section{Questão da Fidelização}

Nenhuma das empresas estudadas apresenta conceitos e aplica políticas ou programas de fidelização, nem mesmo formula objetivos específicos no âmbito dessa dimensão.

A agência "J" considera difícil concretizar esses elementos por envolver intensa atividade de controle, sem o qual corre-se o risco de um programa do gênero deixar de funcionar, bem como de apresentar efeitos opostos ao desejado.

A agência "P" não aplica programas com o propósito de obter fidelização, por trabalhar unicamente com um destino exótico, e considerar pouco provável que os turistas queiram retornar com frequiência ao mesmo local.

A não utilização de estratégias de fidelização aponta para uma lacuna no 
aproveitamento de oportunidades de diferenciação, principalmente associadas a empresas de pequeno porte e que operem em nichos específicos de mercado (concentração).

\section{Captação/Contato com Novos Clientes}

A agência "J" não tem procurado mensurar e controlar o volume e a proporção de clientes que requisitam seus serviços usando o mecanismo da internet. Para a agência, a principal desvantagem de estabelecimento de contatos pela internet reside na necessidade de contatos pessoais posteriores para fornecimento de informações pormenorizadas e solução de dúvidas específicas. Além disso, é alegado que o contato pessoal, além de envolver alto potencial de persuasão, permite o ajustamento mais adequado dos serviços ao perfil do cliente. A falta de contato direto, por outro lado, é vista como um fator de risco, pois o cliente pode procurar outros formecedores e canais.

A agência "P" revelou que uma parcela de $50 \%$ do total do fluxo dos clientes é proveniente da internet. Todavia, a agência não tem mensurado quanto pode ter variado o número de clientes em função da internet. A agência alimenta a expectativa de que o acesso via rede virtual aumente expressivamente, trazendo consigo a perspectiva de migração de clientes provenientes da rede convencional de distribuição para a rede eletrônica. Ela reconhece, no entanto, que os gastos em promoção tenderão a aumentar acentuadamente, em virtude dos altos custos de ocupação de espaço na internet e linkagem com sites correlatos.

Ambas planejam ampliar a ação na internet medianie cooperação com fornecedores de serviços - hotéis, por exemplo -, ampliação das informações sobre os destinos e utilização de links em sites que atinjam clientes com o mesmo perfil. As agências reconhecem que os desafios maiores residem em transferir para a rede eletrônica parte do poder de persuasão inerente aos canais convencionais e conseguir a adequação dos serviços à especificidade de cada cliente.

\section{Personalização (Customização)}

Observou-se que ambas as agências interpretam a personalização como o fornecimento de serviços sob medida, da maneira como forem solicitados pelo cliente. Reconhecem essas empresas que a personalização pode incorporar elementos como sala vip, traslado, comitê de recepção, guia exclusivo etc. Entretanto, nenhuma delas comunica tais possibilidades de serviço personalizado.

A agência "J" não considera imprescindível o estabelecimento de uma política de comunicação ao mercado. A agência "P" prefere comunicar individualmente, via telefone. A cada cliente potencial que estabelece contato telefônico com essa última agência, a agência "P” procura explicar que seus serviços são delineados caso a caso.

\section{Custos de Promoção}

As empresas analisadas acompanham o senso comum, que aponta para menores custos na utilização da internet como canal de distribuição e de transação. No entanto, elas admitem que os custos de comunicação podem ser altos e comprometer parcela significativa das receitas, pelo menos nas fases iniciais de uso da internet. Enquanto a agência "J" não revela aumento de seus gastos promocionais, a agência "P" acusa elevação desta modalidade de gasto e expectativa de gastos maiores no futuro.

A agência "J" apresenta ainda outros tipos de custos, advindos da necessidade de estruturação, condizente com a ampliação dos perfis de público que deverá atingir com a internet.

\section{Niveis dos Preços Praticados em funçāo do uso da internet}

A agência "J", embora não acuse alterações nos níveis de preços praticados em razão da internet, prevê queda de preços. Esse decréscimo no valor unitário das vendas deverá ser compensado pela expansão de seu volume. Os serviços vendidos por essa agência possuem características que permitem menor grau de diferenciação, ao contrário do que ocorre com a outra agência estudada. Parte deles, ao menos, já foi intensamente experimentada por seus clientes, havendo, portanto, menor necessidade de informações complexas que demandem aconselhamento. Em relação ao futuro, a agência "J" prevê que, pelo fato de o cliente poder acessar outros sites, a concorrência será maior, pois outras empresas estarão oferecendo os mesmos serviços pelos mesmos meios. $\mathrm{O}$ cliente pode fazer pesquisas e analisar as diversas ofertas de forma objetiva. Com isso, a agência poderá perder negócios.

A agência "P"observou que os consumidores potenciais buscam preços mais baixos. Ela tem se defrontado com um cliente mais bem informado e, aparentemente, mais capacitado a comparar de forma objetiva. Como a agência oferece compostos diversificados, formatados de forma personalizada, não se vê forçada a aceitar pressões por preços menores. Quanto à evolução dos preços, a empresa prevê relativa estabilidade, não observando a existência de pressão baixista, confirmando a teoria segundo a qual há tendência de ocorrer maior competição entre serviços que oferecem baixo grau de diferenciação, sendo, portanto, facilmente substituíveis.

Paralelamente à questão dos preços praticados, há os aspectos relativos à concorrência. A agência "J" prevê maior acirramento das condições competitivas, 
enquanto a agência “P” considera estável o ambiente competitivo.

\section{Consideraçōes Finais}

Com o advento da internet, a configuração dos mercados identifica-se com a ausência de fatores que, em canais tradicionais, permitem a existência de situações típicas de concorrência imperfeita, em que os concorrentes apresentam elementos de diferenciação em suas ofertas. As operações virtuais provocam a criação de fatores indutores, os quais conduzem o mercado a ostentar características típicas do regime de concorrência perfeita. Elementos como proximidade do ponto-de-venda, familiaridade do comprador com o vendedor, ambiente confortável e outros podem ficar diluídos com as operações na rede.

Com a perda de importância de características do ponto-de-venda, ganham relevância os aspectos ligados ao produto, os quais podem permitir, ou não, a diferenciação do ofertante. As ameaças e as oportunidades aparecem de forma distinta para os agentes de viagens, de acordo com o tipo de serviço que transacionam.

Compras reflexivas, como viagens, podem ser alimentadas por diferentes tipos de informações. Em um extremo aparecem produtos e serviços, cujas compras requerem pesquisas e informações externas e podem ser transmitidas de forma objetiva: são os "bens de conhecimento". No outro extremo encontram-se os que são comprados mediante inspeção ou experimentação pessoal: são os "bens de experimentação". Compras frequientes aumentam a possibilidade de adequação do serviço à internet, podendo significar a substituição do intermediário.

No caso de "bens de conhecimento", que necessitam informações objetivas, a internet é um meio propício de realização de funções de transação e de comunicação. Nesse caso, a internet é uma ameaça para o agente de viagens, pois o intermediário poderá ser descartado.

Quanto menor for a possibilidade de personalização (customização) e da necessidade de experimentação, mais acirrada será a concorrência, aproximando-se o mercado do regime de concorrência perfeita, em que são menores as possibilidades de diferenciação.

Por outro lado, um "bem de experimentação", que passou a fazer parte do consumo rotineiro para o consumidor, configura-se como um bem de conhecimento. Por exemplo, ordens de compra de bilhetes aéreos de ida-e-volta, para local largamente experimentado, revelam forte tendência para a compra pela internet.

Do composto de serviços vendido pelas agências, as viagens aéreas representam o serviço com menor possibilidade de diferenciação. Caso o consumidor queira um destino já conhecido, aumentam as possibilidades de prescindir do agente de viagens, pois as informações requeridas serão de caráter objetivo. Não há, pois, necessidade de informações complexas tampouco do aconselhamento que substitui a experimentação.

Com o uso da internet como meio de distribuição e transação, a diferenciação em virtude da localização geográfica do ponto-de-venda é eliminada ou, na melhor das hipóteses, diluída. De um lado, produtos indiferenciados tenderão a compor mercados com intensa concorrência e, por isso, deverão ter margens de comercialização mais estreitas; de outro, produtos diferenciados, como viagens a destinos exóticos, tenderão a ter suas margens de comercialização elevadas, pois os consumidores estarão dispostos a pagar mais por produtos que proporcionem os benefícios que eles consideram mais importantes.

Por fim, as agências de viagens que tornarem disponíveis produtos e serviços diferenciados, em seu site na internet, terão grandes possibilidades de serem escolhidas por consumidores que estejam dispostos a pagar mais para desfrutarem os melhores momentos de lazer e de entretenimento em suas viagens.

A internet, como poderosa rede de informações, a um só tempo equilibra as condições de oferta e realça as diferenças entre produtos e serviços, quer quanto a preço, quer quanto às suas características peculiares.

\section{Referências Bibliográficas}

ASSOCIAÇÃO BRASILEIRA DAS AGÊNCIAS DE VIAGENS-ABAV. 1996. Perfil dosetorde agênciasde turismo

e perspectivas para o mercado depois do plano real. São Paulo.
BARBIERI, J. C. 1997. Revista de Administraçāo de Empresas, Fundąāo Getúlio Vargas, v. 37, n. 1, p. 66-77.

jan./mar.
BENI, M. C.. 1998. Análise estrutural do turismo. São Paulo: SENAC

CHAMBERLIN, E.H. 1950. The theory of monopolistic competition. Cambridge, MA: Harvard University Press. EVANS, Philip B. \& WURSTER, Thomas S. 1999. Strategy and the new economics of information. In: TAPCOSTT, D. (Editor). Creating value in the network economy. Boston: EUA.

ITZSIMMONS, James A. 1998. Service management: operation, strategy \& information technology. 2. ed. Irwin McGraw Hill

列 of Retailing, 67 (Summer)

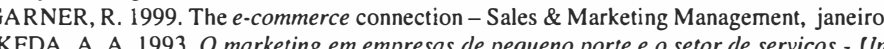

arketing em empresas de pequeno porte e o setor de serviços - Um estudo em agências de viagens. Tese (Dou
sidade de São Paulo.

LAMBIN, Jean-Jacques. 2000. Marketing estratégico. Lisboa, Portugal: Mc Graw-Hill.

LEVITT, Theodore. 1980. Marketing success through differentation of everything: Harvard Business Review, v.58, p. $83-91$

LOVELOCK, C. H. 1991. Servicesmarketing. 2. ed. NY: Prentice-Hall International Editions.

MACHÍN, C. A. 1993. Marketing y turismo. Madrid: Editorial Sintesis.

NIELSEN Media Research Internet Demographics Survey. 1998

ORGANIZAÇAO MUNDIAL DO TURISMO - OMT. 1997. Tendencias de los mercados turisticos. Madri: Espanha PARASURAMAN, 1991. Marketing Research. Massachusetts, EUA: Addison-Wesley.

PETERSON, R. A. et al. 1997. Exploring the implications of the Internet for consumer marketing. Journal of Academ of Marketing Science, v. 25, n.4.

PORTER, M. 1989. Vantagem Competitiva. Rio de Janeiro: Campus Ltda.

POON, A. 1994. Tourism, technology and competitive strategies. Wallingford, G. B: Cab International.

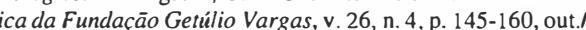
dez.

TOLEDO Geraldo L L 1996 Consulting Group / Shop. Org. de outubro. 
Resenhas

As resenhas foram desenvolvidas pelos alunos do Mestrado em Ciências da Comunicação da ECA/USP, na disciplina "Evolução da Pesquisa Científica em

Turismo: o pensamento internacional e a realidade brasileira".

INTRODUÇÃO À ECONOMIA DO TURISMO (2000). ARENDIT, Edmilson José. Campinas. Ed. Alínea. 142 p.

Segundo a Organização Mundial do Trabalho - OMT - , o turismo é o setor econômico que mais crescerá nos próximos anos, no Brasil e no mundo. Trata-se de um fenômeno associado a uma sociedade em que há aumento do tempo livre das pessoas e expansão cada vez maior de empresas transnacionais.

Esse processo vem fomentando a criação de cursos de turismo no País, de nível técnico e superior, de modo que há demanda crescente por publicações específicas de caráter didático - um problema a ser enfrentado pelas instituições de ensino, tanto pelo fato de ser uma área de conhecimento multidisciplinar e ainda em formação, como pela carência de materiais apropriados para serem usados nesses cursos. É exatamente com a finalidade de cobrir a falta de "textos sintéticos que auxiliassem os alunos no entendimento dos princípios básicos da economia e sua relação com o turismo" que o autor, professor de economia em cursos de turismo, produziu sua obra.

A obra, portanto, com caráter introdutório, corrobora para apresentar, em três capítulos, os conceitos básicos de economia e a lógica que rege o relacionamento dos agentes econômicos que atuam no setor de turismo, embasando-se na teoria microeconômica e macroeconômica.

No primeiro capítulo, apresentam-se, rapidamente, os aspectos históricos do turismo, citando sua evolução desde a Antiguidade até os dias de hoje, passando pela Babilônia, Grécia, Roma, outros locais na Europa e norte da África, considerandose também o surgimento do Capitalismo e suas fases - o Mercantilismo e as grandes viagens para o Oriente, a Revolução Industrial e a expansão das ferrovias -, o processo de formação dos centros urbano-industriais e conflitos das duas grandes guerras mundiais, a expansão do transporte aéreo e de outros meios na segunda 